Bond University

Research Repository

\title{
Structural behaviour of hardwood veneer-based circular hollow sections of different compactness
}

Gilbert, Benoit P.; Underhill, lan D.; Fernando, Dilum; Bailleres, Henri; Miller, Dane

Published in:

Construction and Building Materials

DOI:

10.1016/j.conbuildmat.2018.03.105

Licence:

CC BY-NC-ND

Link to output in Bond University research repository.

Recommended citation(APA):

Gilbert, B. P., Underhill, I. D., Fernando, D., Bailleres, H., \& Miller, D. (2018). Structural behaviour of hardwood veneer-based circular hollow sections of different compactness. Construction and Building Materials, 170, 557569. https://doi.org/10.1016/j.conbuildmat.2018.03.105

\section{General rights}

Copyright and moral rights for the publications made accessible in the public portal are retained by the authors and/or other copyright owners and it is a condition of accessing publications that users recognise and abide by the legal requirements associated with these rights.

For more information, or if you believe that this document breaches copyright, please contact the Bond University research repository coordinator. 

SECTIONS OF DIFFERENT COMPACTNESS

\author{
Benoit P. Gilbert ${ }^{(1)}$, Ian D. Underhill ${ }^{(1)}$, Dilum Fernando ${ }^{(2)}$, Henri Bailleres $^{(3)}$, Dane Miller ${ }^{(4)}$ \\ (1) School of Engineering and Built Environment, Griffith University, Australia \\ (2) School of Civil Engineering, The University of Queensland, Australia

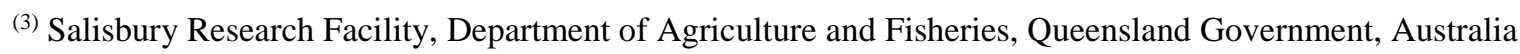 \\ (4) Faculty of Society \& Design, Bond University, Australia \\ Corresponding author: b.gilbert@griffith.edu.au
}

Abstract: This paper presents the capacity and structural behaviour of hardwood veneer-based circular hollow sections (CHS) tested in bending, shear and compression. The sections were manufactured from early to mid-rotation (juvenile) Gympie messmate (Eucalyptus cloeziana) plantation thinned logs. In total twenty-one $167 \mathrm{~mm}$ Outside Diameter $(\mathrm{OD}) \times 1.2 \mathrm{~m}$ long CHS were manufactured in seven sets of three nominally identical sections. Two different wall thicknesses were investigated to produce nine compact and twelve more slender cross-sections. The sections were also manufactured in three different structural grades. A sudden failure mode was observed in the compression zone of the slender sections tested in bending. In compression, the compact sections showed a ductile behaviour, while the slender sections showed a more brittle behaviour, with the sections bursting into longitudinal strips. While a relationship was observed between the bending and compressive capacities, and the structural grade, no such relationship was noticed for the shear capacity. Comparison to steel and concrete sections of similar outside diameter proved that the timber sections are the most efficient in terms of bending and compressive capacity to linear weight ratio. The timber sections fall behind their steel and concrete counterparts in terms of shear efficiency, however they still have enough shear capacity for representative structural applications. 


\section{INTRODUCTION}

To develop a market for low-value, small diameter, early to mid-rotation (juvenile) hardwood plantation logs, veneer-based hollow sections are currently being developed in Australia [1-3], see Figure 1. These sections have the potential to be used in structural applications $[1,3]$ and are seen, for instance, as a potential solution for utility poles [1] and the main frame of buildings. They have the advantage of having an efficient cross-sectional shape, are sustainable [4-6], and able to be manufactured in usable lengths [2] and cross-sectional sizes that are no longer available in sawn timber.

In the literature, various hollow timber structural solutions have been investigated. They include (i) spirally winded veneer-based Circular Hollow Section (CHS) [7-9], (ii) fibre-reinforced moulded wooden tubes [10-14], (iii) octagonal tubes from composite wood flakes panels [15], (iv) nonagon tubes from knot free pine wood strips [16], (v) "wood rings" reinforced with glass epoxy [17] and

(vi) LVL type CHS for temporary geotechnical soil nailing systems [18]. Commercially, veneerbased hollow timber solutions are also available, either limited to small diameter cross-sections (up $100 \mathrm{~mm}$ ) [19] or short lengths (up to $1,000 \mathrm{~mm}$ ) [20].

To confidently use the new sections in structural applications, research is still needed to fully understand their structural behaviour, failure modes and reliability. In particular, bending tests performed on $145 \mathrm{~mm}$ Outside Diameter (OD) $\times 15 \mathrm{~mm}$ (wall thickness) Laminated Veneer Lumber (LVL) type CHS showed that the sections can experience a sudden failure in the compression zone, with the sections opening up [1]. While this failure mode has been observed in hollow trees [21], it is not typical of solid timber beams which usually reach a maximum bending moment due to tensile rupture [22]. The sudden compressive failure mode is likely attributed to the semi-compactness of the cross-section in [1] which led to local buckling and cross-section ovalisation (Brazier effect [23]). The relationship between the cross-sectional slenderness and structural behaviour requires further attention. 
Consequently, the structural behaviour and failure modes of veneer-based timber CHS of various

51 cross-sectional slenderness are experimentally investigated in bending, shear and compression in this paper. In total twelve $167 \mathrm{~mm}(\mathrm{OD}) \times 12.5 \mathrm{~mm}$ (wall thickness), referred to as "slender", and nine $167 \mathrm{~mm}(\mathrm{OD}) \times 25 \mathrm{~mm}$ (wall thickness), referred to as "compact", $1.2 \mathrm{~m}$ long CHS were manufactured from early to mid-rotation (juvenile) Gympie messmate (Eucalyptus cloeziana) plantation thinned logs. The veneer grain was orientated in the same direction and along the member longitudinal axis for all sections except for one type of the slender sections. For this section, cross-banded veneers were used in this case to potentially increase the section local buckling capacity. To study the effect of the timber elastic stiffness on the new products' structural behaviour, the CHS were manufactured in three different structural grades. The grades were solely based on the veneers' Modulus of Elasticity (MOE).

The paper initially introduces the investigated cross-sections and the associated manufacturing process. Secondly, the test set-ups for all investigated loading cases are presented. Thirdly, the structural behaviour, capacities and failure modes of the slender and compact sections are analysed and counterparts.

\section{INVESTIGATED CROSS-SECTIONS}

\subsection{General}

In total, twenty-one nominal $167 \mathrm{~mm}(\mathrm{OD}) \times 1.2 \mathrm{~m}$ long veneer-based CHS were manufactured from two half cross-sections following the process described later in Section 2.2. Randomly selected nominal $1.2 \mathrm{~m}($ Long $) \times 1.2 \mathrm{~m}($ Wide $) \times 2.5 \mathrm{~mm}$ (Thick) Gympie messmate rotary peeled veneer sheets were delivered and then cut parallel to the grain direction (i.e. perpendicular to the length of the veneer ribbon) into four $300 \mathrm{~mm}$ wide strips. The longitudinal dynamic MOE of each veneer sheet 
was then measured using a non-destructive resonance method [24]. To do so, the second cut strip per veneer sheet was simply supported on rubber bands and impacted with a hammer in its longitudinal direction. The sample natural frequency was recorded using a microphone and analysed using the software $\mathrm{BING}^{\circledR}$ (Beam Identification by Non-destructive Grading) [25]. Figure 2 shows a photo of the set-up. Before assessing the dynamic MOE, the veneers were conditioned in a temperature controlled room set at $22^{\circ} \mathrm{C}$.

Based on their measured MOE, the delivered veneer sheets were divided into three stacks of equal number of veneers. This classified the veneers into three grades referred to as "Grade 1" for the lower MOE (13 GPa < MOE $\leq 19 \mathrm{GPa})$, “Grade 2" for the intermediate MOE (19 GPa < MOE $\leq 21 \mathrm{GPa})$ and "Grade 3" for the higher MOE $(21 \mathrm{GPa}<\mathrm{MOE} \leq 25 \mathrm{GPa})$.

The twenty-one CHS were manufactured in seven sets of three nominal identical samples. Per set, the half cross-sections of the three nominally identical CHS were manufactured from the same veneer sheets which were glued in the exact same order. Precisely, for each veneer sheet, three $300 \mathrm{~mm}$ wide strips out of four were used in the CHS manufacturing process. The remaining strip was used to determine the material properties of the half cross-sections as detailed in Sections 2.2 and 3.2. The seven sets consisted of:

- Three sets of nominal $167 \mathrm{~mm}(\mathrm{OD}) \times 12.5 \mathrm{~mm}$ (5-ply) slender CHS manufactured from Grade 1 (Set "S_G1"), Grade 2 (Set "S_G2") and Grade 3 (Set "S_G3") veneers. In these sets, the veneers' grain is orientated in the same direction and along the longitudinal axis of the section.

- One set of nominal $167 \mathrm{~mm}(\mathrm{OD}) \times 13 \mathrm{~mm}$ slender CHS. To potentially increase the section local buckling capacity, a cross-banded configuration was used. Four $2.5 \mathrm{~mm}$ thick Gympie messmate hardwood Grade 2 veneers were orientated along the longitudinal axis of the section and three 1 mm thick cross-banded softwood Hoop pine (Araucaria cunninghamii) veneers were inserted between the hardwood veneers to form a 7-ply configuration. This set is referred to as "S_G2_Cross". 
- Three sets of nominal $167 \mathrm{~mm}(\mathrm{OD}) \times 25 \mathrm{~mm}$ (10-ply) compact CHS manufactured from Grade 1 (Set “C_G1"), Grade 2 (Set “C_G2") and Grade 3 (Set “C_G3”) veneers. In these sets, the veneers' grain is orientated in the same direction and along the longitudinal axis of the section. An examples of a compact and slender CHS is shown in Figure 1 (a).

Note that while the wall the slender sections is quite thin, fire protection may be achieved by gluing sacrificial low MOE veneers to the outside of the sections, therefore protecting the load carrying part of the CHS.

\subsection{Manufacturing process}

The manufacturing process detailed in $[18,26]$ and used to manufacture the samples tested in $[1$, 2] has been improved in this study. A similar process to the one described in $[18,27]$ has been followed. After assessing the dynamic MOE of the veneers, the veneers were moved out of the temperature controlled room and stored in an indoor environment (structure laboratory) until gluing. To form the half cross-sections, resorcinol formaldehyde structural adhesive was applied to the veneer strips at ambient temperature and humidity. The veneer stacks were then inserted into a $167 \mathrm{~mm}$ Internal Diameter (ID) CHS PVC pipe and cold-pressed for 24 hours by a fire hose inserted into the PVC pipe and pressurised at 1.2 $\mathrm{MPa}$ with water. Figure 3 illustrates the manufacturing process.

As rotary peeled veneers have the natural tendency to curl about their loose side (i.e. the one in contact with the blade of the peeling lathe), the loose side of a veneer was always glued herein to the tight side of the next veneer. The tight and loose veneer sides therefore formed the outside and inner faces of the manufactured hollow cross-sections, respectively. The two half cross-sections forming a complete CHS were then butt jointed together using structural epoxy resin (Figure 1 (b)) due to its good gap properties which can compensate for non-strict parallelism of the two half cross-sections. For alignment, the glue-line incorporated biscuit joints every $400 \mathrm{~mm}$. 
Additionally, to determine the mechanical properties of the material of the timber sections, two $500 \mathrm{~mm} \times 300 \mathrm{~mm}$ flat panels were also manufactured for each half-section. The panels were manufactured from the same veneer sheets used to produce the half cross-sections and were glued in the exact same layering order.

\section{TESTING METHODOLOGY}

\subsection{General}

Per manufactured set, one section was tested in bending, one in shear and one in compression. The following sub-sections introduce the material testing methodology and the test set-ups of the CHS for each one of the investigated loading cases.

Before testing, all samples were conditioned in the same temperature controlled room as the veneers when the dynamic MOE was assessed, for a minimum period of one month. The temperature in the room was set at $22^{\circ} \mathrm{C}$. For all scenarios, excluding the CHS tested in compression, pieces were cut and weighed immediately after testing from selected test samples to determine the timber moisture content at the time of testing. The oven-dry methodology in the Australian and New Zealand standard AS/NZS 1080.1 [28] was followed.

\subsection{Material properties}

\subsubsection{Tension tests}

139 From the first flat panel of each half cross-section, a maximum of five nominal $10 \mathrm{~mm}$ wide $\times 100$ $140 \mathrm{~mm}$ long (gauge length) coupon (dog bone) samples were CNC cut. The samples were similar to the 141 ones recommended by the ASTM D3500-14 [29] and were used to estimate the tensile strength of 142 each half cross-section. The ends of the samples were clamped in the jaws of a $500 \mathrm{kN}$ capacity MTS 143 universal testing machine and tested in tension at a constant strain rate to reach failure in 3-6 mins.

144 The tensile strength $\sigma_{\text {tens }}$ of each coupon was calculated as, 


$$
\sigma_{\text {tens }}=\frac{F_{\max }}{W_{t} t_{t}}
$$

146 where $F_{\max }$ is the maximum recorded force, $W_{t}$ and $t_{t}$ are the measured width and thickness of the 147 coupons, respectively.

\subsubsection{Compression tests}

149 The second flat panel of each half cross-section was used to determine the compressive strength 150 of the material. To avoid buckling of the samples corresponding to the slender CHS, the $12.5 \mathrm{~mm}$ 151 thick panels were cut in two and glued together using resorcinol formaldehyde structural adhesive to 152 form nominal $25 \mathrm{~mm}$ thick panels. The panels corresponding to the compact CHS were left un153 touched. Up to four $80 \mathrm{~mm}$ (Wide) $\times 150 \mathrm{~mm}$ (Long) rectangular samples were cut per panel for 154 material testing.

155 The samples were tested in compression in a $500 \mathrm{kN}$ capacity MTS universal testing machine at a 156 constant strain rate to reach the peak stress in 3-5 mins. Specifically, the samples were positioned 157 between a fixed bottom platen and an upper platen mounted on a spherical seat, which could rotate, 158 so as to provide full contact between the platens and the specimens. Note that before testing, the ends 159 of the samples were cut with a high quality fine cut circular saw blade to ensure a uniform contact 160 pressure between the platens and the samples.

161 Similar to Eq. (1), the compressive strength $\sigma_{c o m p}$ of each sample was calculated as,

$$
\sigma_{\text {comp }}=\frac{F_{\max }}{W_{c} t_{c}}
$$

163 where $F_{\max }$ is the maximum recorded force, $W_{c}$ and $t_{c}$ are the measured width and thickness of the 164 samples, respectively. 


\subsection{Bending tests}

\subsubsection{Test set-up}

To measure the bending strength and stiffness of the timber CHS, the sections were tested in a similar manner to the one reported in [2]. A pair of four reinforced quarter steel tubes, $240 \mathrm{~mm}$ long, were designed and manufactured to rigidly clamp each end of the CHS, as shown in Figure 4. Each steel clamp was bolted to a steel Rectangular Hollow Section (RHS) to form a 2,360 mm long beam. To avoid local crushing of the timber CHS and fully transfer the moment from the steel RHS to the timber with minimum stress concentration, two part epoxy resin was poured at the steel-timber connection (i) in the inside of the timber CHS filled with plywood and (ii) on the outside of the timber CHS to match the inside diameter of the four quarter steel tubes. On top of the friction forces applied by the clamps to the timber, screws connecting the steel to the timber were also added to further prevent sliding of the timber sections in the clamps. The overall test set-up is shown in Figure 5.

The sections were then tested in a $500 \mathrm{kN}$ capacity MTS universal testing machine, with the load being applied to the steel RHS, as shown in Figure 5. The tests were run in displacement control and reached failure in 3-4 minutes for the slender sections and 5-6 minutes for the compact sections. For all tests, the butt joints between two half-sections lied in the horizontal plane.

Three Laser Displacement Sensors (LDS) recorded the vertical displacement at the bottom fibre of the timber sections for simplicity in the test set-up. Additionally, two $30 \mathrm{~mm}$ strain gauges (SG) recorded the mid-span longitudinal strain at the top (compression) and bottom (tension) fibres of the timber CHS. A third $30 \mathrm{~mm}$ strain gauge recorded the mid-span tangential stress to better apprehend the cross-sectional deformation. Locations and numbering of all LDS and strain gauges are given in Figure 5 (b). The $300 \mathrm{~mm}$ distance between LDS was chosen so the edge LDS are away for the clamping ends while placing the LDS the further away from each other.

\subsubsection{Evaluations}

The applied moment $M$ to the hollow timber sections is calculated as, 


$$
M=\frac{\left(F+F_{w}\right) L_{1}}{2}
$$

192 where $F$ is the total applied load, $F_{w}=2.37 \mathrm{kN}$ is the gravity load applied by the steel rig (including 193 the steel CHS and measured at the points of application of the load) and $L_{1}=455 \mathrm{~mm}$ is given in 194 Figure $5(\mathrm{~b})$. The bending capacity $M_{\mathrm{b}}$ is defined as the maximum applied moment $M$ and the bending strength $f_{b}$ is obtained from the well-known equation,

$$
f_{b}=\frac{M_{b}}{Z}
$$

where $\mathrm{Z}$ is the section modulus calculated from the measured cross-sectional dimensions, assuming a perfect composite action between the two half cross-sections.

The relative displacement $\delta$ of the timber sections is calculated from the displacements $\delta_{1}, \delta_{2}$ and $\delta_{3}$ recorded by the LDS number 1, 2 and 3, respectively, as,

$$
\delta=\delta_{1}-\frac{\delta_{2}+\delta_{3}}{2}
$$

The static MOE $E_{s}$ parallel to the grain of the timber sections is calculated from the bending stiffness $E_{s} I_{s}$ defined as,

$$
E_{s} I_{s}=\frac{k_{t} d^{2}}{2}
$$

where $I_{s}$ is the second moment of area of the CHS (calculated from measured dimensions), $d$ is given in Figure 5 (b) and $k_{t}$ is the stiffness of the linear part of the experimental moment-displacement curve $207(M-\delta)$, calculated by performing a linear regression between $5 \mathrm{kN} . \mathrm{m}$ and $20 \mathrm{kN} . \mathrm{m}$ for the compact 208 sections and $2.5 \mathrm{kN} . \mathrm{m}$ and $15 \mathrm{kN} . \mathrm{m}$ for the slender ones. Note that Eq. (6) assumes that the relative 209 displacement $\delta$ is measured at the neutral axis. Yet, using the relative displacement measured in this 210 study at the bottom fibre of the section provides accurate results, with a maximum error in determin211 ing $E_{s} I_{s}$ of less than $0.5 \%$. 


\subsection{Shear tests}

\subsubsection{Test set-up}

214 To estimate the shear strength of the timber CHS, the sections were tested in three point bending, 215 similarly to the tests performed in [1]. The sections were simply supported with a distance $L=500$ $216 \mathrm{~mm}$ between two consecutive loads, as shown in the schematic test set-up in Figure 6. To avoid local 217 crushing of the sections, two part epoxy resin (combined with plywood) was poured inside the CHS 218 at the load application point and supports. The butt joints between two half cross-sections lied in the 219 horizontal plane. For each set, the half cross-section which was in compression in the bending test 220 (Section 3.3) was also in compression in the shear test. The tests were performed in a $500 \mathrm{kN}$ capacity 221 MTS universal testing machine in displacement control and reached failure in 6-8 minutes for all sections but for S_G3 which was tested at a higher strain rate and reached failure in 2 minutes.

\subsubsection{Evaluations}

The shear strength $f_{s}$ of the hollow timber sections is calculated using the shear area of a CHS as $[30]$,

$$
f_{s}=\frac{F_{\max }}{\frac{3}{2} A\left(\frac{R_{o}^{2}+R_{i}^{2}}{R_{o}^{2}+R_{o} R_{i}+R_{i}^{2}}\right)}
$$

where $F_{\max }$ is the total maximum applied load, $A$ is the measured CHS cross-sectional area, and $R_{o}$ and $R_{i}$ are the measured CHS external and internal radii, respectively. The shear capacity $V_{s}$ is calcu-

229 lated as $F_{\max } / 2$.

\subsection{Compressive tests}

\subsubsection{Test set-up}

To measure the compressive strength and stiffness of the timber CHS, the sections were tested in compression in a $10 \mathrm{MN}$ capacity MTS universal testing machine. The sections were positioned between a fixed bottom platen and an upper platen mounted on a spherical seat, which could rotate. The 
samples were mechanically sanded flat in a milling machine before testing to ensure a uniform contact

236 pressure between the platens and the CHS. The tests were performed in displacement control and 237 reached failure in 3-4 minutes for the slender sections and 5-6 minutes for the compact sections. The 238 test set-up is shown in Figure 7.

239 Two diametrically opposed $30 \mathrm{~mm}$ strain gauges, glued parallel to the column axis, each located 240 in the middle of a half cross-section and $150 \mathrm{~mm}$ from the bottom end of the sections, recorded the 241 longitudinal deformation. Strain gauges numbering is given in Figure 7.

\subsubsection{Evaluations}

243 The compressive stress $\sigma$ of the hollow timber sections is calculated as,

$$
\sigma=\frac{F}{A}
$$

where $F$ is the applied load and $A$ is the measured CHS cross-sectional area. The compressive capacity $R_{\mathrm{c}}$ and strength $f_{c}$ are defined as the maximum applied force and compressive stress, respectively. The static MOE $E_{s}$ is calculated by performing a linear regression on the linear part of the stressstrain curve $(\sigma-\varepsilon)$ between $5 \mathrm{MPa}$ and $40 \mathrm{MPa}$. The strain $\varepsilon$ is calculated as the average of strains $\varepsilon_{1}$ and $\varepsilon_{2}$ from strain gauges 1 and 2, respectively.

\section{RESULTS AND DISCUSSION}

\subsection{Material properties}

Table 1 gives the tensile and compressive strengths of the material of each half cross-section of each investigated set. As the veneer MOE increases with the grade, so typically does the measured material strength [31]. For the LVL samples, the compressive strength ranges from 58.6 MPa (S_G1) to 77.9 MPa (C_G3 and S_G3), and the tensile one from 96.3 MPa (C_G1) to 135.8 (C_G3). Due to 
timber samples, the Coefficients of Variation $(\mathrm{CoV})$ of the tensile test results are typically higher than the ones of the compressive test results. The average oven dry moisture content at the time of testing of the tension and compression samples is reported in Table 2.

\subsection{Bending tests}

\subsubsection{Capacities and failure modes}

The bending capacities $M_{b}$ and strengths $f_{b}$ for all CHS tested in bending are reported in Table 3, 264 along with the measured static $\operatorname{MOE} E_{s}$ (Eq. (6)) and observed failure modes. Two of the slender sections (S_G1 and S_G3) failed in buckling of the compression fibre, with the section opening up, as shown in Figure 8 (a). Slender S_G2 and compact C_G1 sections failed in tensile rupture, as shown in Figure 8 (b). The cross-banded CHS (C_G2_Cross) prematurely failed in the butt joint between the two half cross-sections, as shown in Figure 8 (c). This weak zone was only observed for all testing configurations in C_G2_Cross, as later reported in Sections 3.4 and 0. In all other sections and sections tested in $[1,2]$, failure never developed in the butt joint. For compact sections C_G2 and C_G3, the steel clamps did not provide sufficient restraints and the sections ultimately slid at the steel-timber connections, leading to shear failure, as shown in Figure 8 (d). However, the maximum bending stresses reached for these two sections are higher than the bending strengths $f_{b}$ of all other tested sections. It is therefore very likely that the maximum recorded moments are within a few percent of the bending capacities $M_{b}$ of the sections. Noting that these maximum recorded moments represent lower bound values of $M_{b}$, their values are conservatively taken for $M_{b}$ herein for both C_G2 and C_G3 sections. For all sections, the bending strength typically increases with the veneer MOE (or grade).

The compact sections reached on average a bending strength $f_{b} 18 \%$ higher than the one of the slender sections of the same grade. This result is attributed to different material strengths between sections (Table 1) and possibly to the section compactness. Indeed, when buckling develops in the compression zone of the slender sections, it would result in a loss in stiffness of the section wall, 
consequently inducing a shift of the neutral axis and a higher stress in the tension zone. The sections would eventually fail in the compression zone (S_G1 and SG_G3) or tension zone (S_G2), whichever zone is the weakest. Such phenomenon would not occur for compact sections for which the compressive zone only experiences plasticity without buckling, as typically observed in timber beams [22]. A similar tensile failure mode to the one experienced in timber beams would be therefore expected.

More investigations are needed to (i) fully comprehend the mechanisms involved in the observed failure modes of the slender sections, (ii) validate the hypothesis in the above paragraph and (iii) quantify the influence of the cross-sectional geometry, timber compressive and tensile strengths on the full section capacity. Numerical models, similar to the one developed in [1], can be used to predict the capacity of compact sections.

Note that the cross-banded section (S_G2_Cross) has a bending strength $f_{b}$ and static MOE $E_{s} 9 \%$ and $55 \%$, respectively, lower than the ones of the slender section of the same grade (S_G2). Crossbanded veneer-based CHS would gain further structural optimisation, such as number and thickness of the cross bands.

\subsubsection{Behaviour}

Figure 9 plots the Moment-Displacement curves $(M-\delta)$ of all investigated sections. While a large non-linear behaviour is observed for the compact sections, it is limited for the slender sections, except for the cross-banded one. As outlined in Figure 9, when failure occurred the moment suddenly dropped for all sections. This observed drop for the two slender sections failing in buckling of the compression zone (S_G1 and S_G3) is due to the sections opening up.

Figure 10 (a) shows the readings of the two strain gauges glued in the section longitudinal axis (SG 1 and SG 3). Timber elements loaded in tension typically exhibit a linear behaviour until fracture suddenly occurs at the maximum tensile strength, and the strain recorded on the tension zone (SG 3) 
306 is consequently almost linear. Plasticity occurred on the compression side (SG 1) at an applied mo307 ment of about 20-25 kN.m and 12-15 kN.m for the compact and slender sections, respectively. This 308 corresponds to bending stresses of about $60 \mathrm{MPa}$ to $75 \mathrm{MPa}$, i.e. of the same order of magnitude of 309 the material compressive strengths reported in Table 1. Due to the buckling of the compression zone 310 for S_G1 and S_G3, reading of Strain gauge 2 reached a plateau for these sections at about 12,000 to $311 \quad 16,000 \mu \varepsilon$.

312 The transverse strain recorded by SG 2 is plotted in Figure 10 (b). The figure mainly indicates that

313 the transverse strain significantly increased when plasticity damage occurred in the compression zone. 314 The strain reversal experienced for S_G1 and S_G3 is likely attributed to the buckling and ovalisation 315 of the cross-sections.

316 The average oven dry moisture content at the time of testing of the sections tested in bending is 317 reported in Table 2.

\subsection{Shear tests}

319 Table 4 gives the experimental shear capacities $V_{s}$ and strengths $f_{s}$ for all investigated sections. All 320 sections failed in the timber except S_G2_Cross which failed in the butt joint between the two half 321 cross-sections. The two observed failure modes are shown in Figure 11. All sections reached a similar 322 shear strength of $10 \mathrm{MPa},+/-7 \%$, indicating that contrary to the bending tests, the grade does not 323 influence the shear capacity. Note that despite S_G2_Cross failing in the butt joint, it still reached a 324 strength of 10.4 MPa. Further optimisation of the cross bands layering may improve the shear capacity 325 of the CHS.

326 In terms of shear capacities, the slender sections sustained shear forces up to $32 \mathrm{kN}$ and the com327 pact ones up to $60.8 \mathrm{kN}$.

328 The average oven dry moisture content at the time of testing of the sections tested in shear is reported in Table 2. 


\subsection{Compressive tests}

331 The compressive stress-strain curves $(\sigma-\varepsilon)$ of all sections are plotted in Figure 12. Two different 332 types of curves are observed resulting in two different failure modes. The compact sections showed 333 a large non-linear plastic behaviour, with the load reaching a plateau before gradually decreasing. A 334 portion of the section wall ultimately locally buckled in a compression type failure mode, as shown 335 in Figure 13 (a). This led to a sudden drop of the load with the section remaining in one single piece. 336 For the slender sections, a plastic behaviour usually started to develop but premature failure (i.e. 337 before the load reached a plateau as for the compact sections) suddenly occurred with the sections 338 bursting into (i) two half cross-sections, with the failure occurring in the butt joint, for S_G2_Cross 339 and (ii) six to seven strips for all remaining slender sections. The latter failure mode is shown in 340 Figure 13 (b) and was also observed in $[13,32]$ for formed wood profiles. The slender sections could 341 therefore not reach their potential full capacity and exhibited a failure mode which should be avoided 342 in structures.

343 The compressive capacities $R_{c}$ and strength $f_{c}$ for all tested sections are reported in Table 5. The 344 ratios of $f_{c}$ to the average material compressive strength $\sigma_{c o m p}$ of the two half cross-sections (reported 345 in Table 1) are also given in the table. Similar to the bending tests, the compressive strength increases 346 with the veneer MOE (grade). Interestingly, both slender and compact sections reached a capacity 347 higher, up to $20 \%$, than the one of the average measured compressive strength of the material. This 348 observation is in contradiction with the length effect $[33,34]$ encountered in timber structures for 349 which the larger the tested volume, the lesser the capacity. The circular shape of the section may 350 delay the compression failure of the cell walls when compared to the results reported in Section 4.1 351 and performed on flat panels. Further investigations are needed to validate and understand the ob352 served phenomena. 
The compressive capacity is high for both section types and reached about $400-500 \mathrm{kN}$ for the 354 slender sections to about $800-1,000 \mathrm{kN}$ for the compact ones. For the compact sections, the capacity 355 is in the range of the design load which may be encountered in the columns of mid-rise timber build356 ings.

357 Also given in Table 5 are the static MOE $E_{s}$ of the sections measured from the linear part of the 358 stress-strain curves $(\sigma-\varepsilon)$ and the ratios of $E_{s}$ measured from the bending tests to the one measured 359 from the compressive tests. The values of $E_{s}$ measured from the two types of tests are consistent with 360 an average difference between the two values of $4 \%$.

\subsection{Comparisons}

362 The structural efficiency of the compact sections is compared herein to the one of steel and rein-

363 forced concrete circular sections of similar (i) diameter and (ii) compressive short-term capacity to 364 the middle grade section C_G2 reported in Table 5. In a first instance only the short-term capacities 365 of the timber section is compared to the ultimate capacities of the steel and concrete counterparts, 366 which are calculated based on relevant Australian standards and without the use of the capacity factor 367 (resistance factor). Effect on long-term loading on the structural efficiency is discussed in a second 368 instance.

369 4.5.1 Comparison to steel CHS

370 A $168.3(\mathrm{OD}) \times 4.8$ (wall thickness) $\mathrm{CHS}$, commercialised by the Australian manufacturer 371 Onesteel [35], is selected for the structural steel section. Its yield stress is $350 \mathrm{MPa}$. Based on the 372 Australian and New-Zeeland standard AS4100 [36], the steel section has ultimate bending, shear and 373 compressive section capacities of $M_{b}=44.8 \mathrm{kN} \cdot \mathrm{m}, V_{s}=311.2 \mathrm{kN}$ and $R_{c}=864.5 \mathrm{kN}$, respectively.

374 Its compressive capacity is within $4 \%$ of the one of C_G2. 
Table 6 compares the ultimate capacities, ultimate capacity to linear weight ratios, bending and axial stiffness of the steel and timber sections. Densities of $805 \mathrm{~kg} / \mathrm{m}^{3}$ for early to mid-rotation Gympie messmate veneers [37] and 7,850 kg/m $\mathrm{m}^{3}$ for steel are used in Table 6. MOE of $200 \mathrm{GPa}$ is also used for the steel in the Table.

Results show that the timber CHS has a short-term bending capacity $M_{b}$ comparable to and only $13 \%$ lower than the one of the steel CHS. Yet, the timber CHS is nearly twice more efficient in terms of ultimate capacity to linear weight ratio. A similar conclusion applies to the compressive capacity to linear weight ratio, with the timber section being more than twice more efficient than the steel CHS. However, the steel CHS is stiffer than the timber profile, with the bending and axial stiffness being 2.7 and 2.1 times higher, respectively.

Regarding the shear, the timber CHS performs poorly when compared to the steel profile. The shear capacity $V_{s}$ and shear to linear weight ratio of the steel CHS are 5.1 and 2.4 times higher, respectively, than the ones of the timber sections. However, for the sizes of timber beams typically encountered in structural applications, i.e. with a span to depth ratio of 20 [38], the shear capacity of the timber section would be high enough. A simply supported, $3.5 \mathrm{~m}$ long, $167 \times 25$ timber CHS loaded with a UDL which fails at an ultimate bending moment of 39.1 kN.m (C_G2 in Table 3), would experience a maximum shear force of $44.7 \mathrm{kN}$. This shear force is $26 \%$ lower than the shear capacity recorded for C_G2 in Table 4.

For long-term loading, the Australian standard AS1720.1 [39] uses a duration of load factor of 0.57. Therefore, using the same $168.3 \times 4.8$ steel CHS and comparing it to the timber CHS, but under long-term loading, the timber section becomes 1.08 and 1.28 times more efficient that the steel CHS in term of bending capacity to linear weight ratio and compressive capacity to linear weight ratio, respectively. In terms of shear capacity to linear weight ratio, the timber CHS now becomes 4.16 times less efficient than the steel CHS. 


\subsubsection{Comparison to reinforced concrete plain circular section}

400 A $167 \mathrm{~mm}$ diameter plain reinforced concrete column, with a concrete compressive strength $f^{\prime}{ }_{c}=$ $40140 \mathrm{MPa}$ and a steel yield stress $f_{y}=500 \mathrm{MPa}$, was designed to standard practices and the Australian 402 Standard AS3600 [40]. While it is understood that a $167 \mathrm{~mm}$ diameter concrete columns would usu403 ally not be used in practice, it still forms a comparative solution to the performance of the timber 404 section. The concrete section is shown in Figure 14, has four N12 longitudinal reinforcing bars and an R10 helix with a pitch of $150 \mathrm{~mm}$. Based on the requirements in [40], a minimum concrete cover of $20 \mathrm{~mm}$ is used with a minimum of $2 \%$ reinforcing steel by gross cross-sectional area. The AS3600 [40] gives ultimate bending, shear and compressive capacities of $M_{b}=11.9 \mathrm{kN} \cdot \mathrm{m}, V_{s}=92 \mathrm{kN}$ and $R_{c}$ $408=946.4 \mathrm{kN}$, respectively, for the concrete section. The compressive capacity of this column is there409 fore within $6 \%$ of the one of C_G2.

410 Table 6 compares the ultimate capacities, ultimate capacity to linear weight ratios, bending and 411 axial stiffness of the concrete and timber sections. The density of concrete for the calculations pre412 sented is $2,400 \mathrm{~kg} / \mathrm{m}^{3}$ and the MOE is $32,8 \mathrm{GPa}$, in accordance to [40].

413 The ultimate bending capacity of the concrete section is significantly lower (3.3 times lower) than 414 the short-term bending capacity of the timber section. This results in the timber section being 22 times 415 more efficient than the concrete one in terms of bending capacity to linear weight ratio. On the other hand, the bending stiffness of the concrete section is twice higher than the proposed timber section and nearly as stiff as the steel section. Note that the small diameter of the concrete column results in 418 the steel being placed close to the neutral axis and therefore an inefficiency in resisting bending mo419 ments is introduced. It is anticipated that for columns of larger diameter, the efficiency of the concrete 420 column for these comparisons would improve.

421 In terms of shear, the shear capacity of the reinforced concrete section is 1.5 higher than the shortterm shear capacity of the timber section, yet the concrete solution is 3.9 less efficient than the timber one in terms of shear capacity to linear weight ratio. 
The concrete section is also the least efficient option in terms of compressive capacity to linear weight ratio. It is 5.6 times and 2.5 less efficient than its timber and steel counterparts, respectively. 426 Nevertheless, it outperformed both the steel (1.5 times higher) and timber (3 times higher) solutions 427 in terms of compressive stiffness.

428 Regarding long-term loading and considering a duration of load factor of 0.57 [39] on the results 429 in Table 6, the concrete section becomes 12.5, 2.2 and 3.2 times less efficient in terms of bending, 430 shear and compressive capacity to linear weight ratios, respectively, when compared to the long-term 431 loading capacities of the timber section.

\section{CONCLUSION}

This paper presented the bending, shear and compression capacities, and structural behaviour, of hardwood veneer-based CHS manufactured from early to mid-rotation (juvenile) Gympie messmate plantation thinned logs. Twelve $167 \mathrm{~mm}(\mathrm{OD}) \times 12.5 \mathrm{~mm}$ (wall thickness), referred to as "slender", and nine $167 \mathrm{~mm}(\mathrm{OD}) \times 25 \mathrm{~mm}$ (wall thickness), referred to as "compact", $1.2 \mathrm{~m}$ long CHS were produced in seven sets of three nominally identical sections. The sections were tested in bending, shear and compression. A sudden failure mode was observed in the compression zone of the slender sections tested in bending, while the compact sections failed in the tension zone. The section had shear capacities of the same order of magnitude, within $7 \%$ of each other. In compression, the compact sections showed a ductile behaviour, while the slender sections catastrophically failed, with the sections bursting into six to seven longitudinal strips. The section compressive strength was observed to be consistently higher than the compressive strength of the material determined from tests per-

445 formed of flat samples. Comparison to steel and concrete sections of similar outside diameter proved that the timber sections were the most efficient in terms of bending and compressive capacity to linear weight ratio. However, while the timber sections fell behind their steel and concrete counterparts in 
terms of shear efficiency, they still showed enough shear capacity for structural applications. The optimisation of the cross-banded layering may improve the shear capacity without significantly impacting the critical structural performances of the CHS.

\section{ACKNOWLEDGMENTS}

The authors would like to thank the Australian Research Council for its financial contribution under project DE140100212. Mr Alexander Mainey glued the timber hollow sections. Mr Maxime Fischer and Mr Julien Husson are also acknowledged for their valuable contribution in preparing the hollow sections for testing and assisting during the tests.

\section{REFERENCES}

[1] B.P. Gilbert, I.D. Underhill, H. Bailleres, A. El Hanandeh, R.L. McGavin "Veneer Based Composite hollow utility poles manufactured from hardwood plantation thinned trees", Construction and Building Materials, 66, 458-466, 2014.

[2] B.P. Gilbert, I.D. Underhill, D. Fernando, H. Bailleres "Structural solutions to produce long timber Veneer Based Composite hollow sections", Construction and Building Materials, 139, 81-92, 2017.

[3] I.D. Underhill, The development and assessment of engineered wood products manufactured from low grade eucalyptus plantation thinnings, $\mathrm{PhD}$ Thesis, Griffith University, Gold Coast, Australia, 2017.

[4] H. Lu, A. El Hanandeh "Life cycle assessment of ACQ-treated Veneer Based Composite (VBC) hollow utility poles from hardwood plantation mid-thinning", Sustainable Production and Consumption, 36-50, 2016.

[5] H.R. Lu, A. El Hanandeh, B.P. Gilbert "A comparative life cycle study of alternative materials perspective", Journal of Cleaner Production, 166, 458-473, 2017.

[6] H.R. Lu, A. El Hanandeh "Environmental and economic assessment of utility poles using life cycle approach", Clean Technologies and Environmental Policy, 19, 1047-1066, 2017.

[7] T. Hata, K. Umemura, H. Yamauchi, A. Nakayama, S. Kawai, H. Sasaki "Design and pilot production of a spiral-winder for the manufacture of cylindrical laminated veneer lumber", Journal of Wood Science, 47, 115-123, 2001. 
[8] P. Berard, P. Yang, H. Yamauchi, K. Umemura, S. Kawai "Modeling of a cylindrical laminated veneer lumber I: mechanical properties of hinoki (Chamaecyparis obtusa) and the reliability of a nonlinear finite elements model of a four-point bending test", Journal of Wood Science, 1-7, 2011.

[9] P. Berard, P. Yang, H. Yamauchi, K. Umemura, S. Kawai "Modeling of a cylindrical laminated veneer lumber II: a nonlinear finite element model to improve the quality of the butt joint", Journal of Wood Science, 1-7, 2011.

[10] J. Wehsener, T. Werner, J. Hartig, P. Haller, "Advancements for the structural application of fiber-reinforced moulded wooden tubes", Proceedings of the RILEM Conference "Materials and Joints in Timber Structures - Recent Advancement of Technology" (Eds.: S. Aicher, H.-W. Reinhardt, H. Garrecht), Stuttgart, Germany, 99-108, 2013.

[11] P. Haller, J. Hartig, J. Wehsener, "Application of moulded wooden tubes as structural elements", Proceedings of the 2014 World Conference on Timber Engineering (Ed.: A. Salenikovich), Quebec City, Canada, Paper ABS684, 2014.

[12] L. Wang, W. Liu, D. Hui "Compression strength of hollow sandwich columns with GFRP skins and a paulownia wood core", Composites Part B: Engineering, 60, 495-506, 2014.

[13] J.U. Hartig, J. Wehsener, P. Haller "Experimental and theoretical investigations on moulded wooden tubes made of beech (Fagus sylvatica L.)", Construction and Building Materials, 126, 527536, 2016.

[14] A. Heiduschke, P. Haller "Fiber-Reinforced Plastic-Confined Wood Profiles Under Axial Compression", Structural Engineering International, 20, 246-253, 2010.

[15] R.D. Adams, G.P. Krueger, A.E. Lund, D.D. Nicholas, "Development of utility poles from composite wood material", Proceedings of the 7th IEEE/PES Transmission and Distribution Conference and Exposition (Ed.: IEEE Service center), Atlanta, U.S.A., 37-40, 1979.

[16] C. Piao, Wood laminated composite poles, PhD Thesis, School of renewable natural ressources, Louisiana State University, Louisiana, U.S.A., 2003.

[17] N.Ç. Yerlikaya, A. Aktaş "Compressive failure of spruce wood rings reinforced with glass epoxy composite", Journal of Forestry Research, 26, 517-522, 2015.

[18] S. Hirschmüller, J. Pravida, R. Marte, M. Flach "Long-term material properties of circular hollow laminated veneer lumber sections under water saturation and cement alkaline attack", Wood Material Science \& Engineering, 1-15, 2018.

[19] Lignotube, LignoTUBE - the new semi-finished product for lightweight construction, http://lignotube.com/description/, 2017
[20]
$\mathrm{K}+\mathrm{W}$
Formholztechnik
$\mathrm{GmbH}$,
Rings
and
Tubes, http://www.formholz.de/produkte_und_loesungen/standardprodukte/ringe_und_roehren, 2017

[21] J. Bond, Foundations of tree risk analysis: Use of the $t / R$ ratio to evaluate trunk failure potential, in: Arborist news, December 2006, pp. 31-34. 
517 [23] L.G. Brazier "On the Flexure of Thin Cylindrical Shells and Other "Thin" Sections", Proceedings 518 of The Royal Society, 116, 104-116, 1927.

519 [24] L. Brancheriau, H. Bailleres "Natural vibration analysis of clear wooden beams: a theoretical review", Wood Science and Technology, 36, 347-365, 2002.

521 [25] CIRAD, BING® (Beam Identification by Nondestructive Grading) software, https://www.picotech.com/library/application-note/non-destructive-testing-of-wood, 2012

[26] I.D. Underhill, B.P. Gilbert, H. Bailleres, R.L. McGavin, D. Patterson, "Structural Veneer Based of the RILEM Conference "Materials and Joints in Timber Structures - Recent Advancement of Technology” (Eds.: A. Aicher, H.-W. Reinhardt, H. Garrecht), Stuttgart, Germany, 577-588, 2013.

[27] S. Hirschmüller, J. Pravida, R. Marte, "Laminated veneer lumber poles for temporary soil nailing- investigation of material properties", Proceedings of the 2016 World Conference on Timber Engineering (Eds.: J. Eberhardsteiner, W. Winter, A. Fadai, M. Pöll), Vienna, Austria, Electronic proceedings, 2016.

[28] AS/NZS 1080.1, Timber - Methods of test - Moisture content, Standards Australia, Sydney, Australia, 2012.

[29] ASTM D3500-14, Standard Test Methods for Structural Panels in Tension, ASTM International, Pennsylvania, USA, 2014.

[30] J. Wardenier, Hollow timber sections in structural applications, (Comité International pour le Développement et l'Etude de la Construction Tubulaire), 2001.

[31] B.P. Gilbert, H. Bailleres, M.F. Fischer, H. Zhang, R.L. McGavin "Mechanical properties of rotary veneers recovered from early to midrotation subtropical-hardwood plantation logs for veneerbased composite applications.", ASCE Journal of Materials in Civil Engineering, 29, 04017194, 2017.

[32] A. Heiduschke, J.M. Cabreo, C. Manthey, P. Haller, E. Gunther, "Mechanical behaviour and life cycle asssessment of fibre-reinforced timber profiles", Proceedings of the Sustainability of Constructions - Integrated approach to lifetime engineering (Ed.: COST Action C25), 338-346, 2008.

544 [33] J.D. Barrett, F. Lam, W. Lau "Size Effects in Visually Graded Softwood Structural Lumber", 545 ASCE Journal of Materials in Civil Engineering, 7, 19-30, 1995.

546 [34] B. Madsen "Length effects in $38 \mathrm{~mm}$ spruce-pine-fir dimension lumber", Canadian Journal of 547 Civil Engineering, 17, 226-237, 1990.

548 [35] Australian Tube Mills, Design Capacity Tables for Structural Steel Hollow Sections, Australian 549 Tube Mills Pty Ltd,, Sunnybank, Australia, 2013.

550 [36] AS 4100, Steel structures Standards Australia, Sydney, Australia, 1998. 
551 [37] R.L. McGavin, H. Bailleres, J. Fehrmann, B. Ozarska "Stiffness and Density Analysis of Rotary 552 Veneer Recovered from Six Species of Australian Plantation Hardwoods", BioRessources, 10, 6395$5536416,2015$.

554 [38] D.L. Schodek, Structures - 2rd Edition, (Prentice-Hall), 1992.

555 [39] AS 1720.1, Timber structures, Part 1: Design methods, Standards Australia, Sydney, Australia, 5562010.

557 [40] AS 3600, Concrete structures, Standards Australia, Sydney, Australia, 2009. 558 


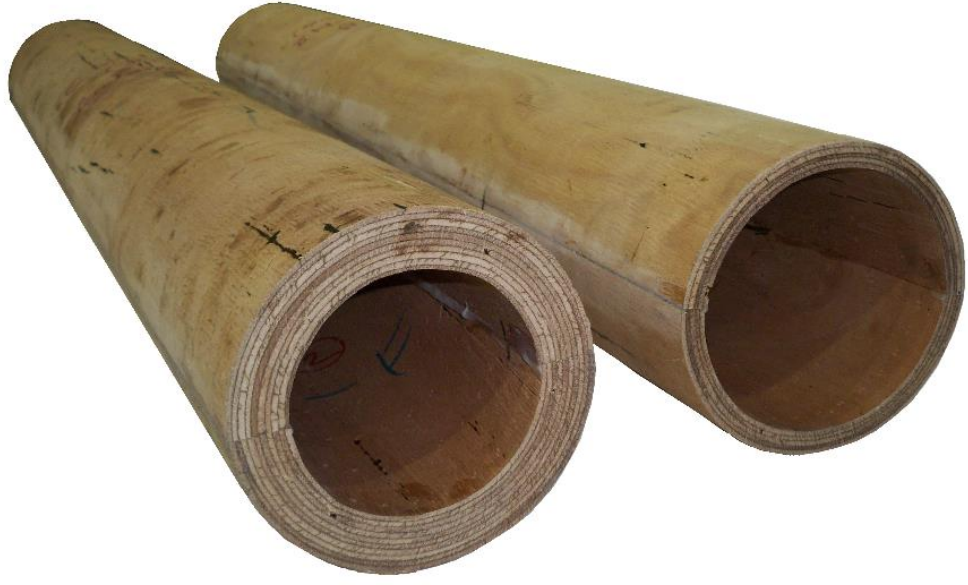

(a)

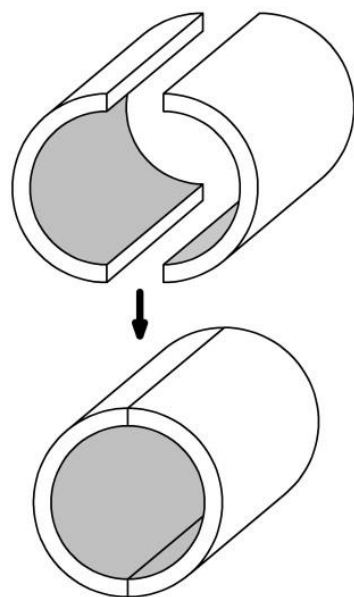

(b)

Figure 1: (a) circular hollow section currently developed in Australia (shown for compact and slender $167 \mathrm{~mm}(O D)$ Gympie messmate) and (b) principle of half cross-sections butt joined together to form a complete CHS

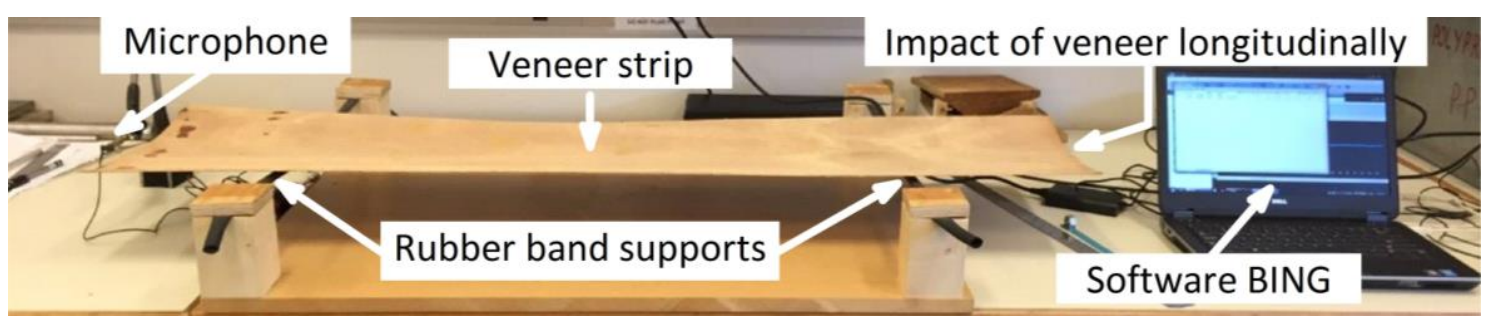

Figure 2: Set-up to assess the longitudinal MOE

Fire hose pressurised with water at $1.2 \mathrm{MPa}$

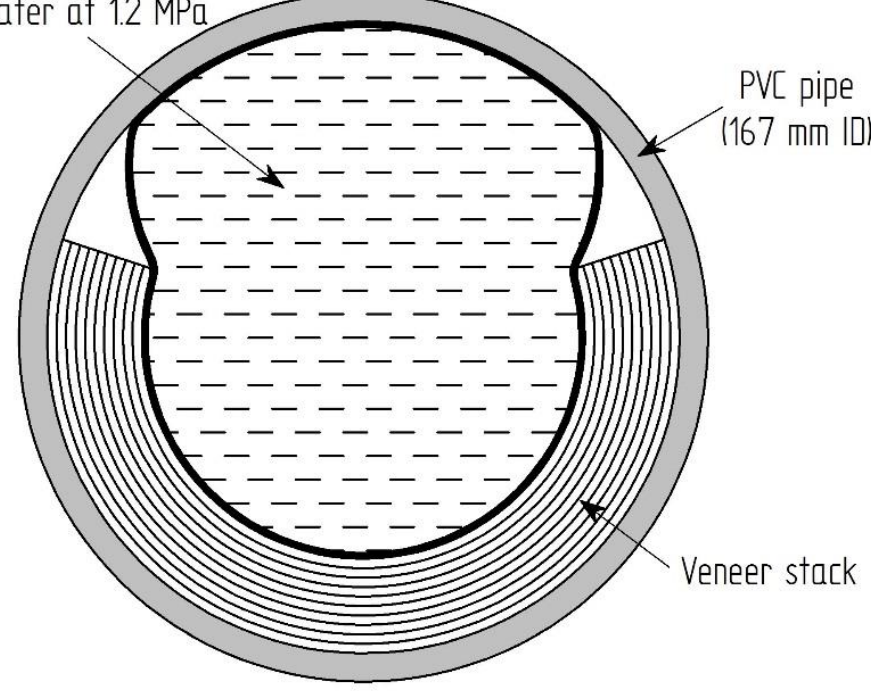




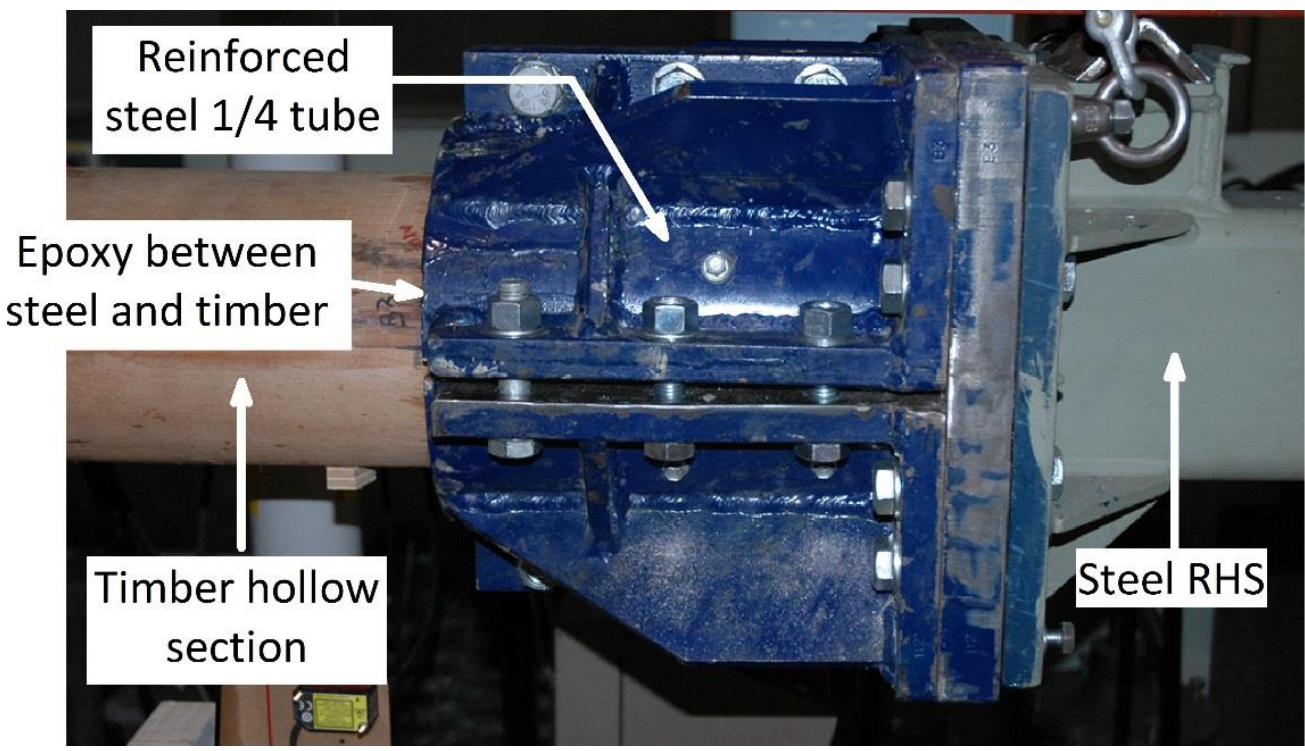

Figure 4: Clamps to connect timber CHS to test rig 


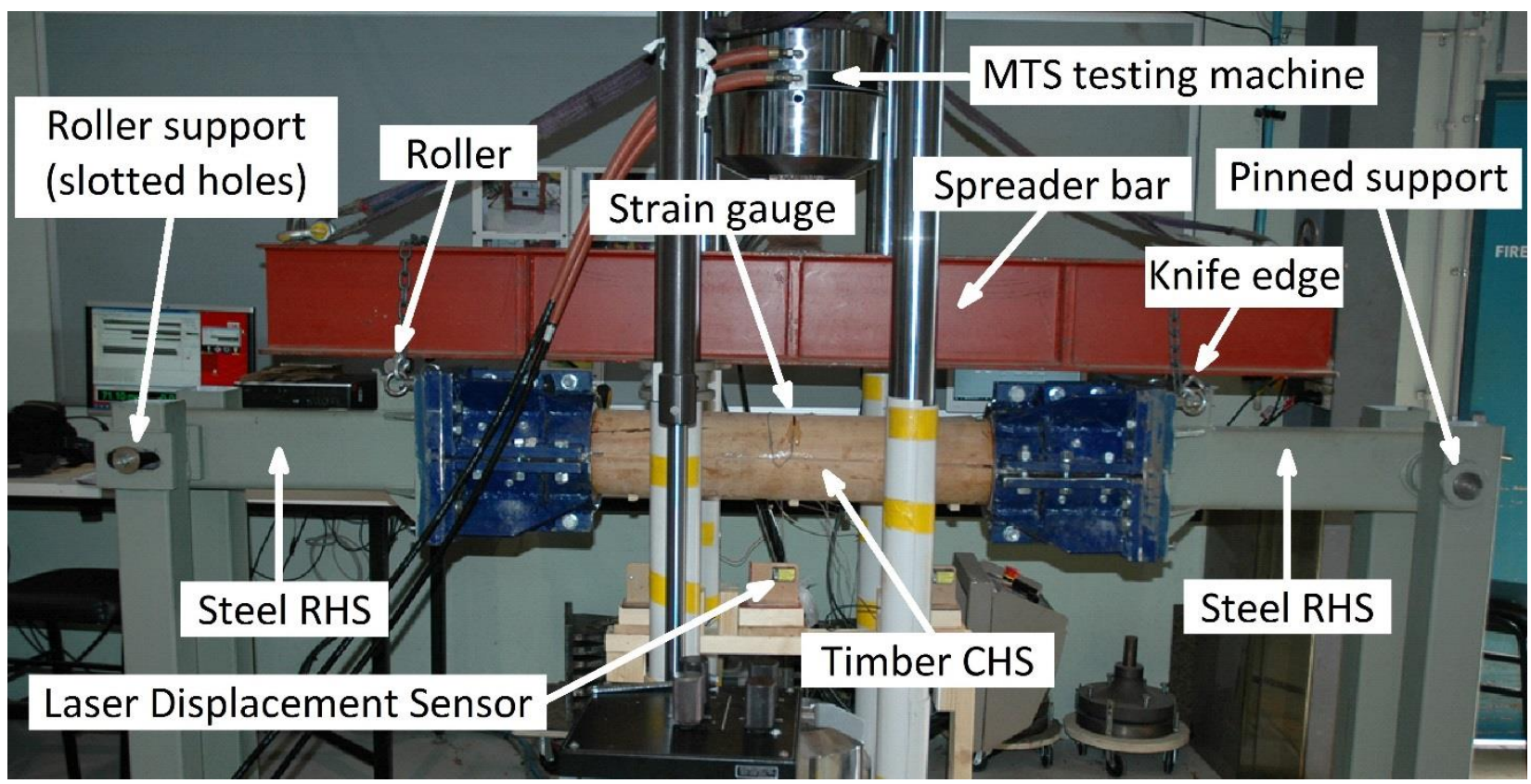

(a)

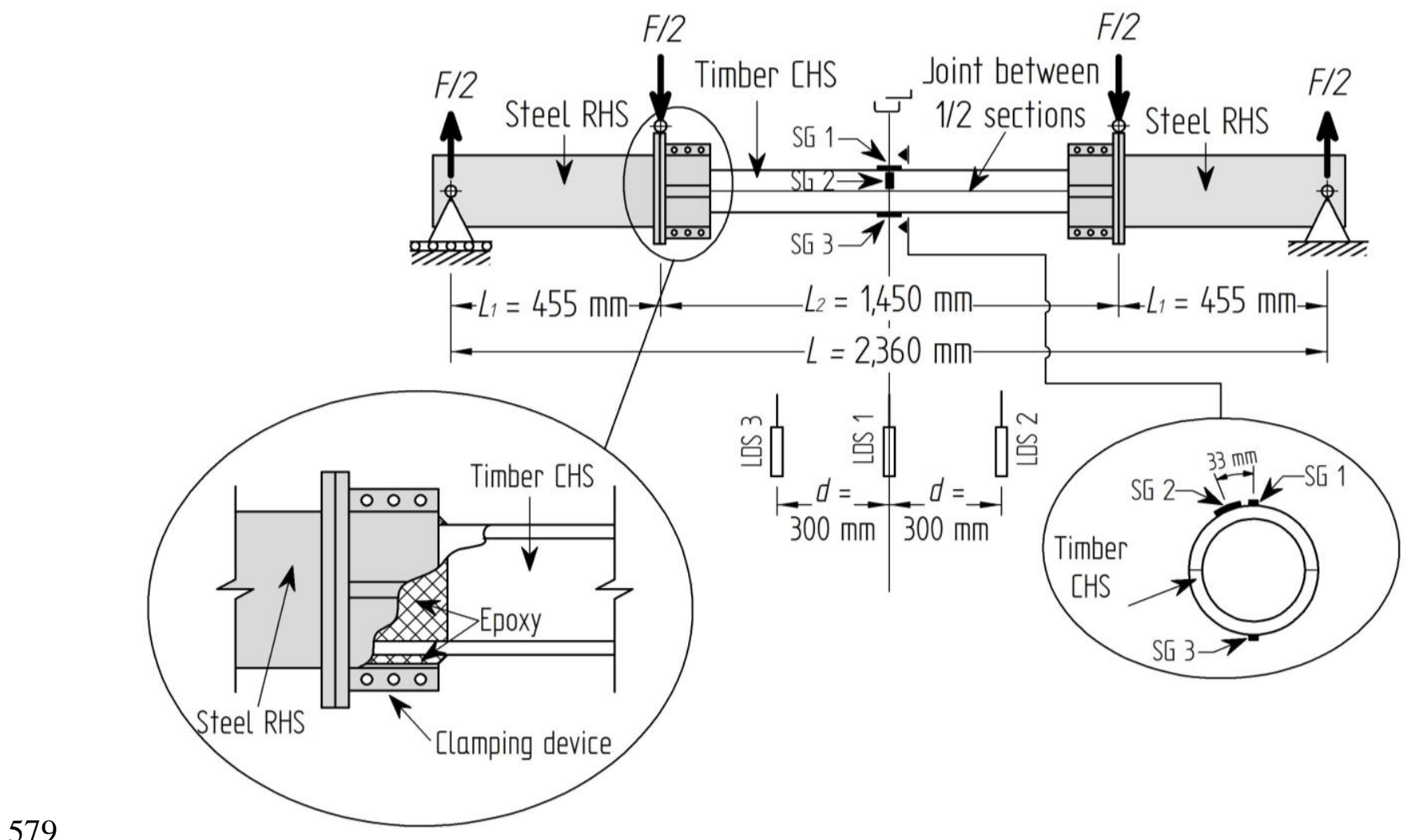

(b)

Figure 5: Bending test set-up, (a) overall picture and (b) schematic 


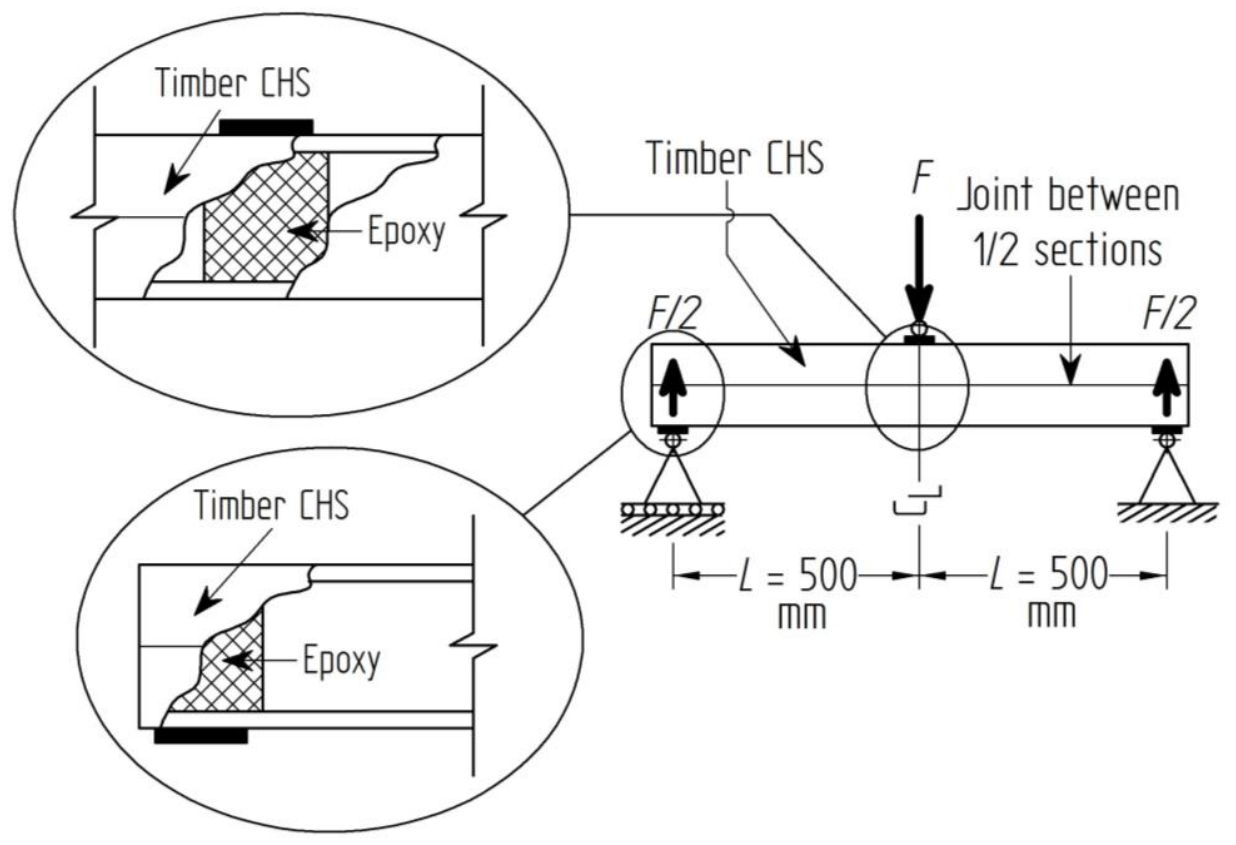

Figure 6: Shear test set-up

585

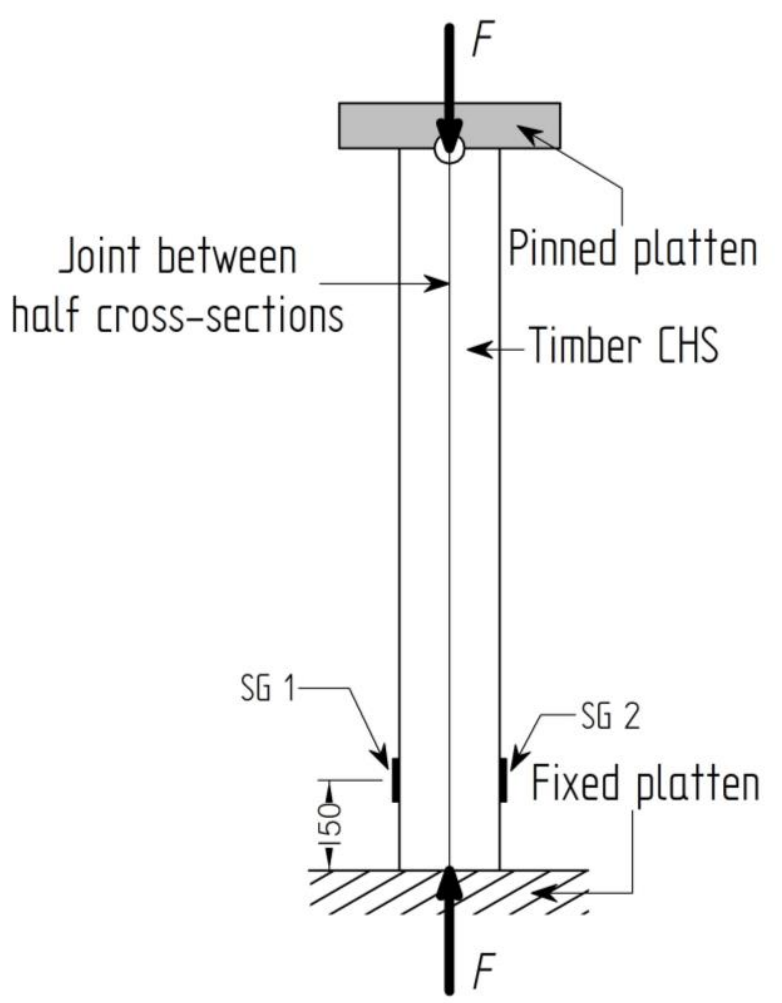

Figure 7: Compression test set-up 


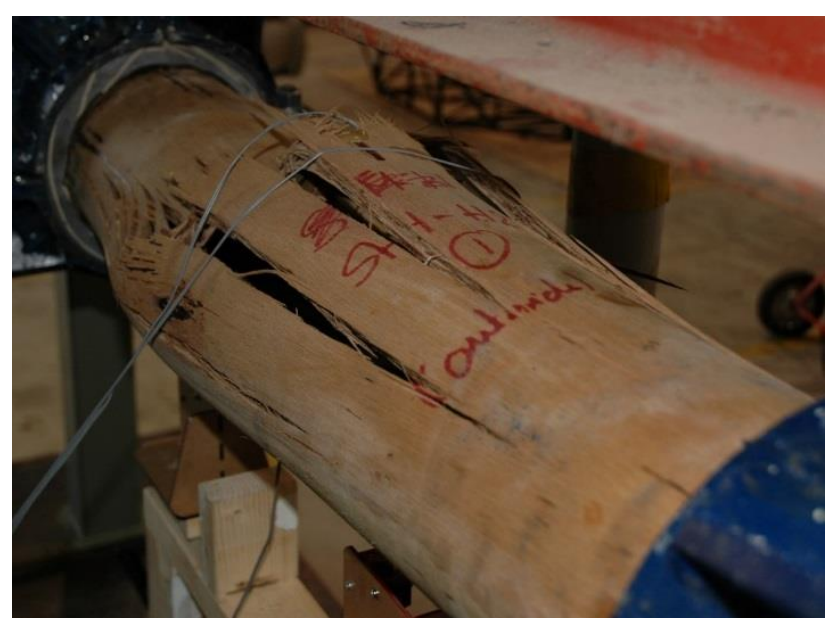

(a)

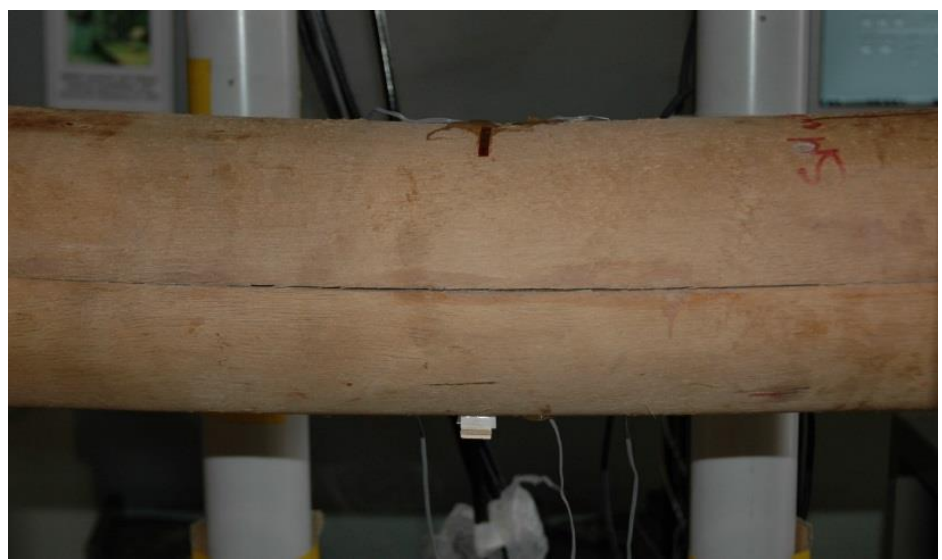

(c)

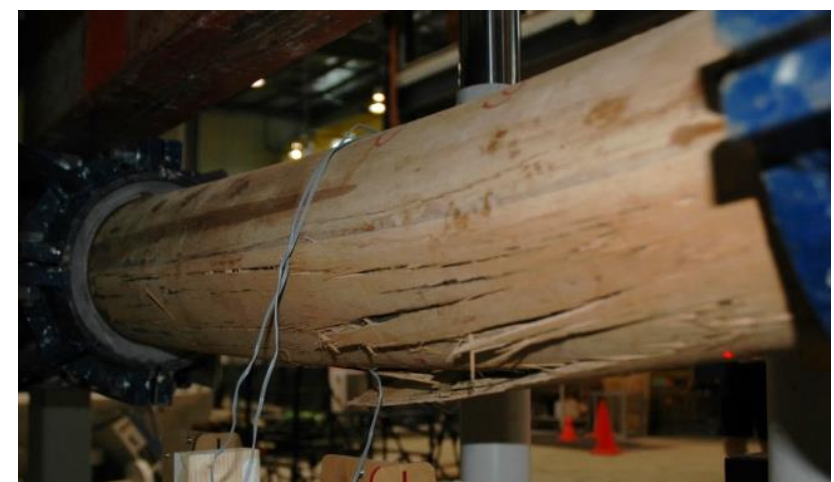

(b)

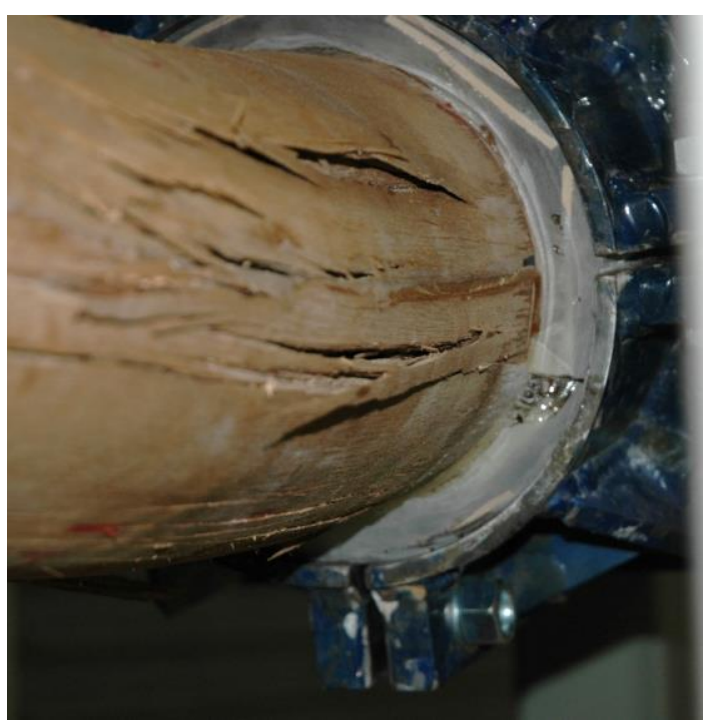

(d)

Figure 8: Bending tests failure modes (a) buckling of the compression zone (shown for $\left.S \_G 3\right),(b)$ Tensile rupture (shown for C_G1), (c) initial failure in the butt joint for C_G2_Cross and (d) premature failure at the steel-timber connections (shown for $C_{-} G 2$ ) 


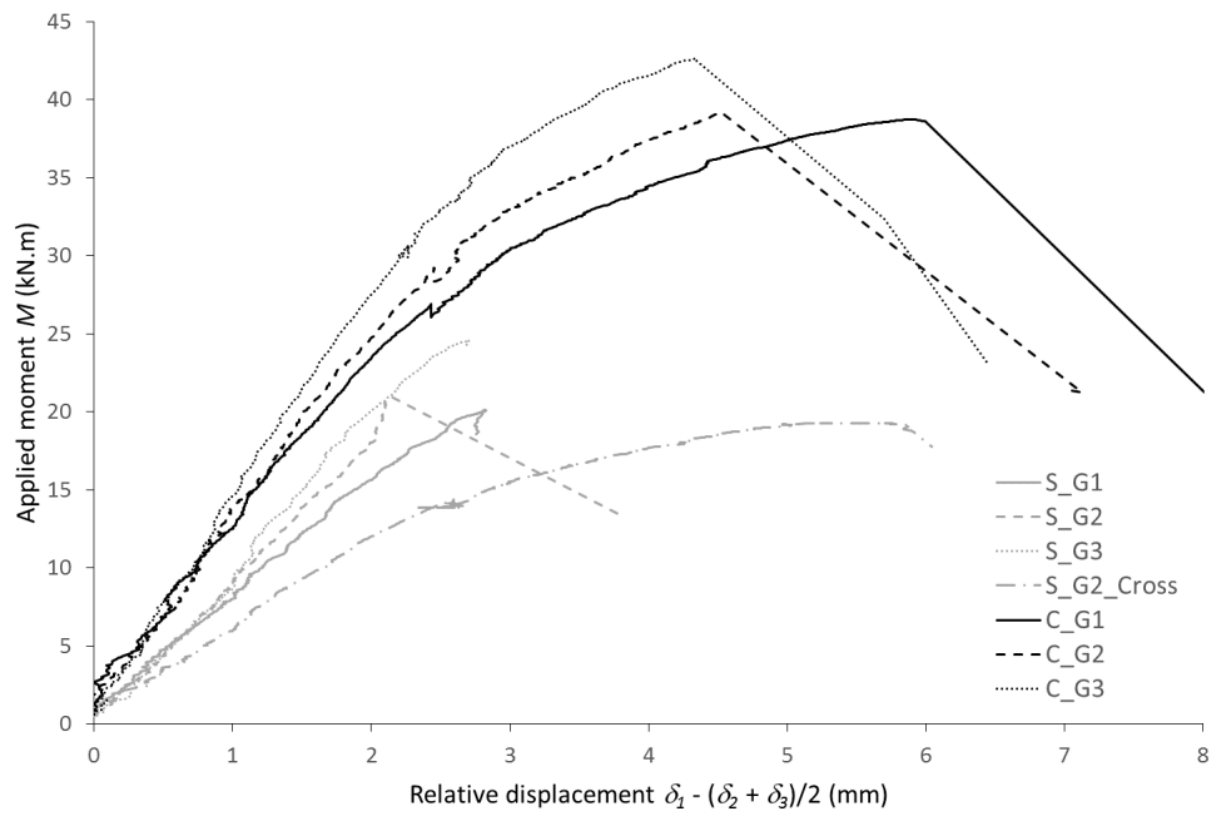

600

Figure 9: Bending tests, Moment-Displacement curves (M- $\delta$ ) for all investigated sections 
603

604

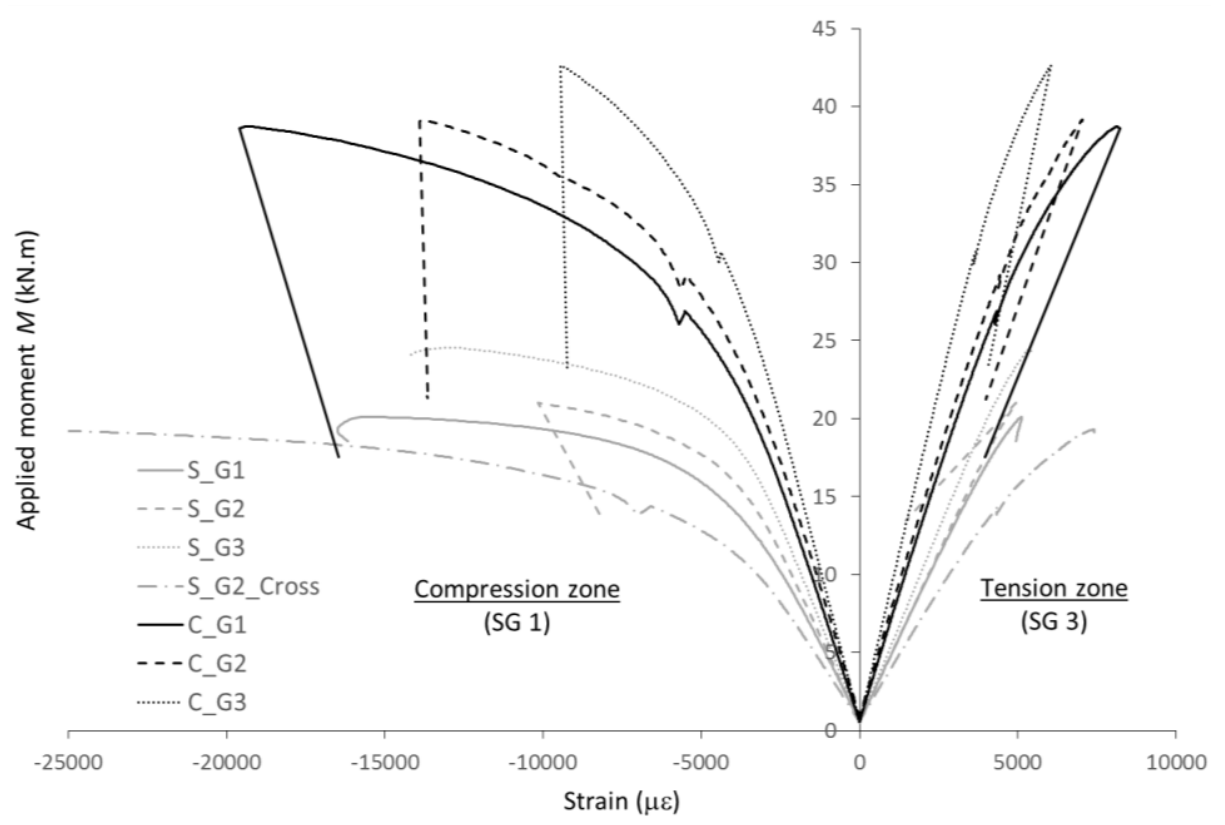

(a)

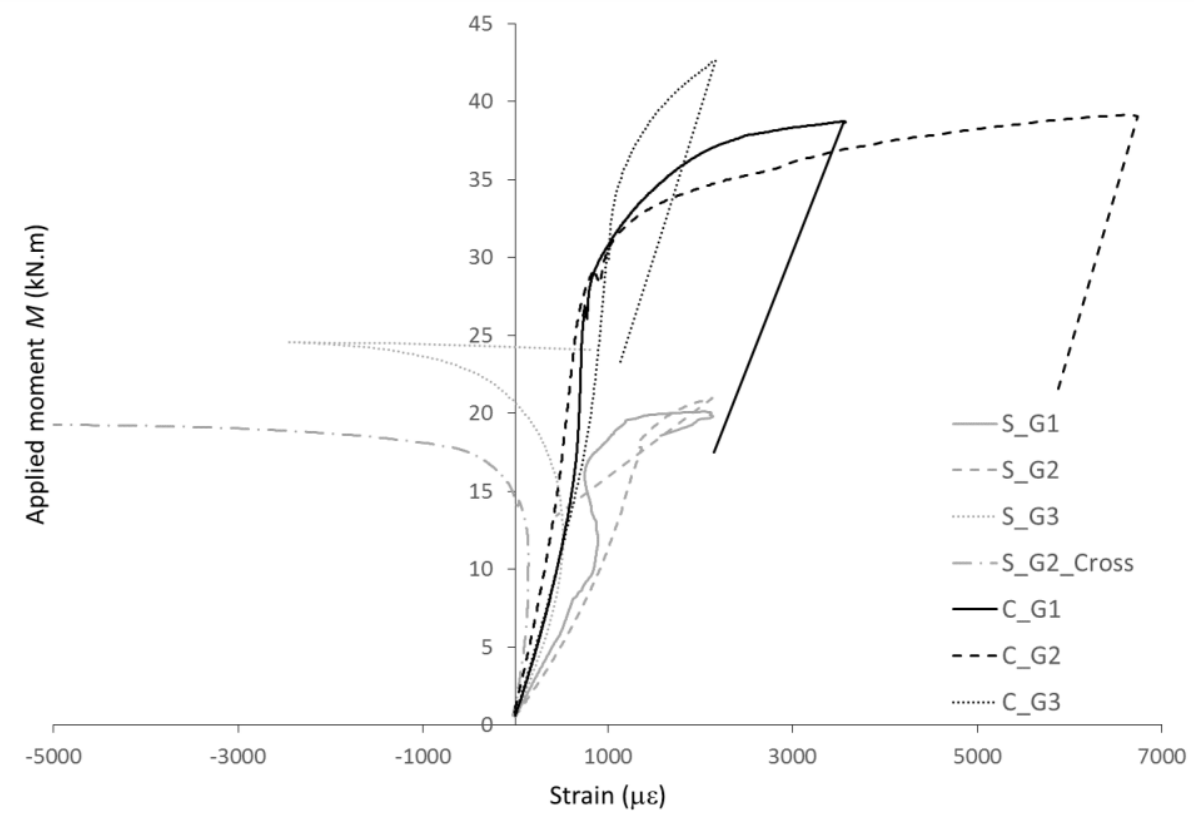

(b)

Figure 10: Bending tests, Strain gauge readings for all investigated sections (a) longitudinal strain gauges (SG 1 and $S G 3$ ) and (b) transverse strain gauge (SG 2) 


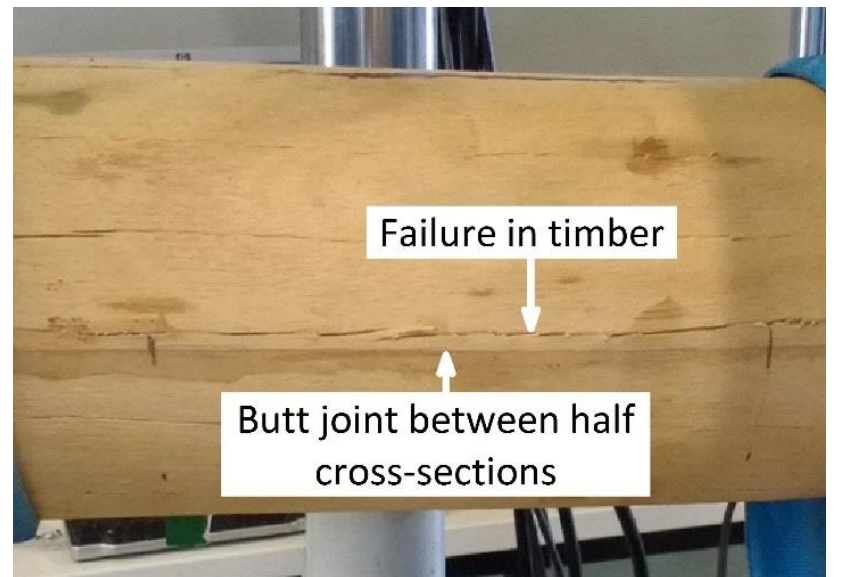

(a)

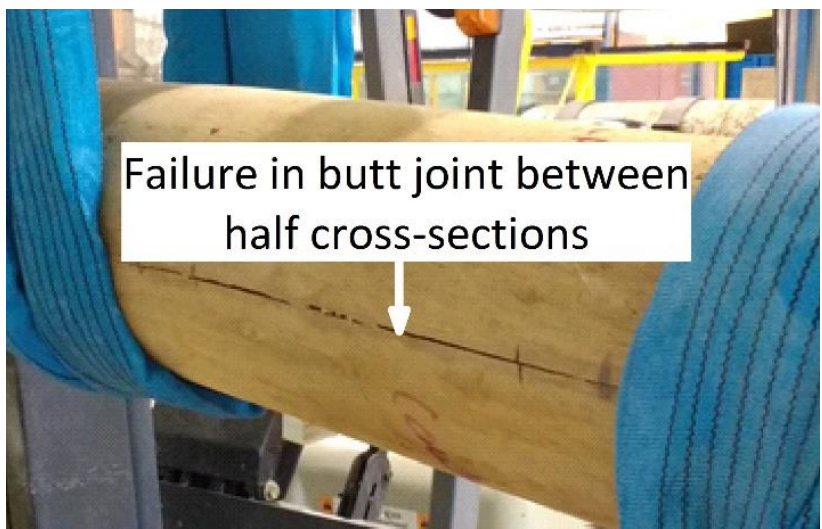

(b)

Figure 11: Shear tests failure modes (a) failure in the timber for all sections but C_G2_Cross

614 (shown for $S_{-} G 3$ ) and (b) failure in the butt joint for C_G2_Cross

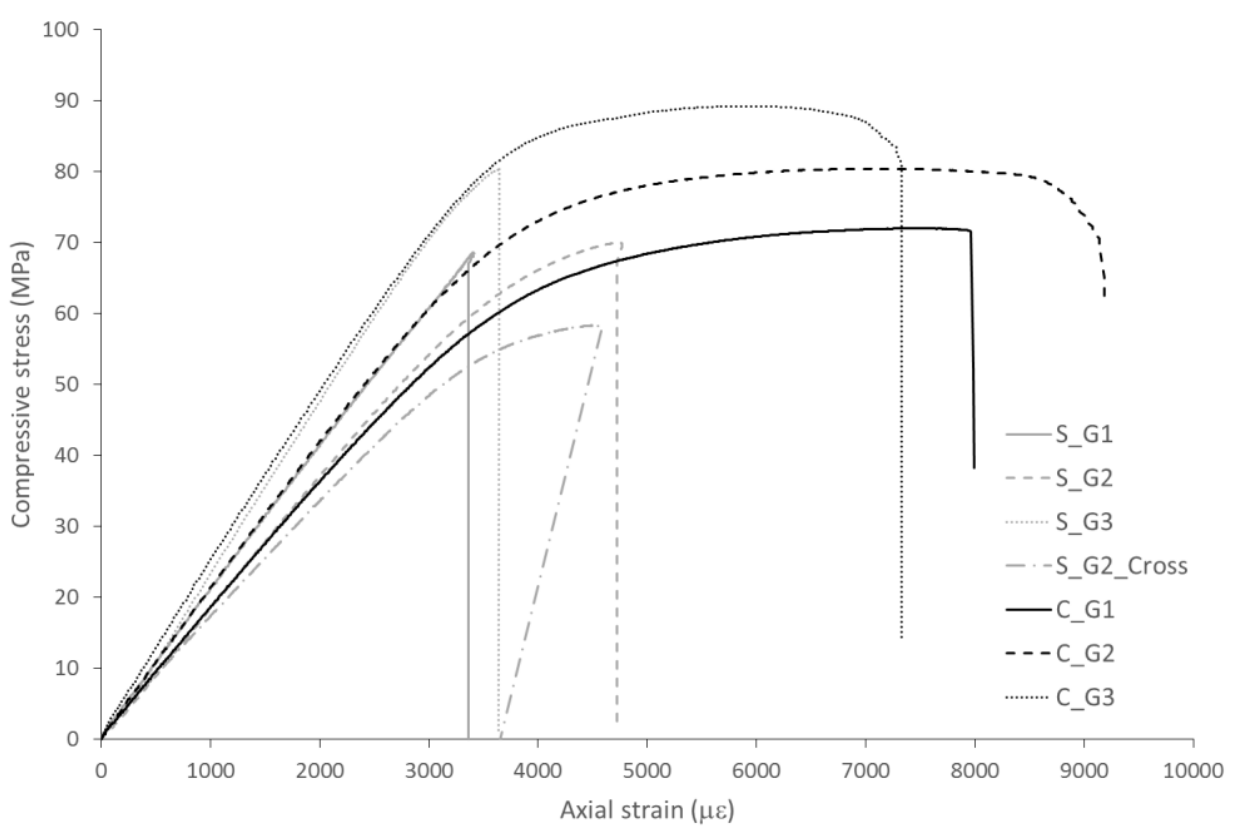




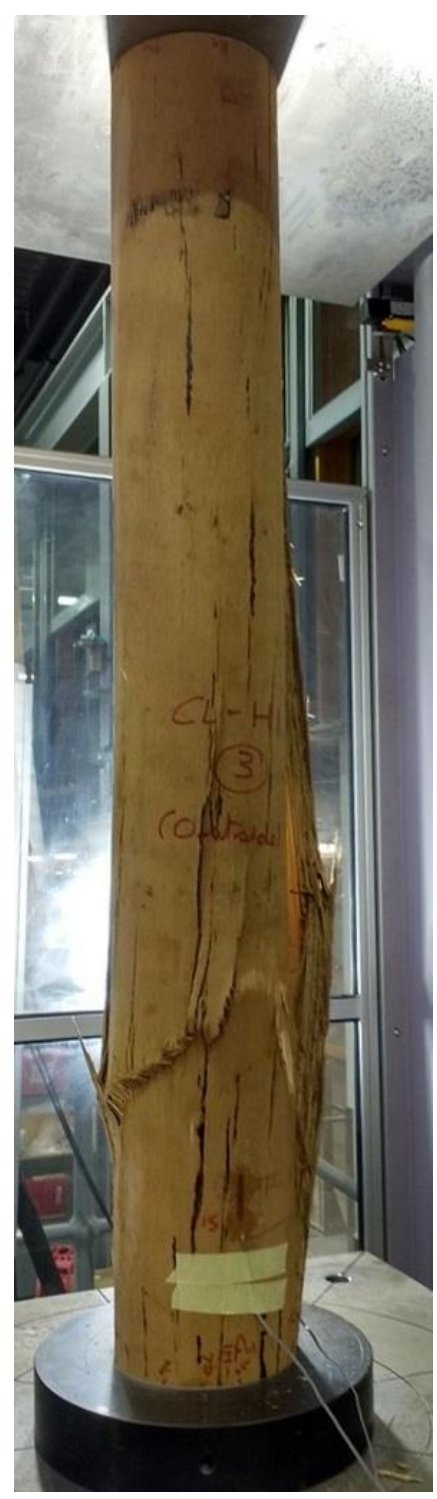

(a)

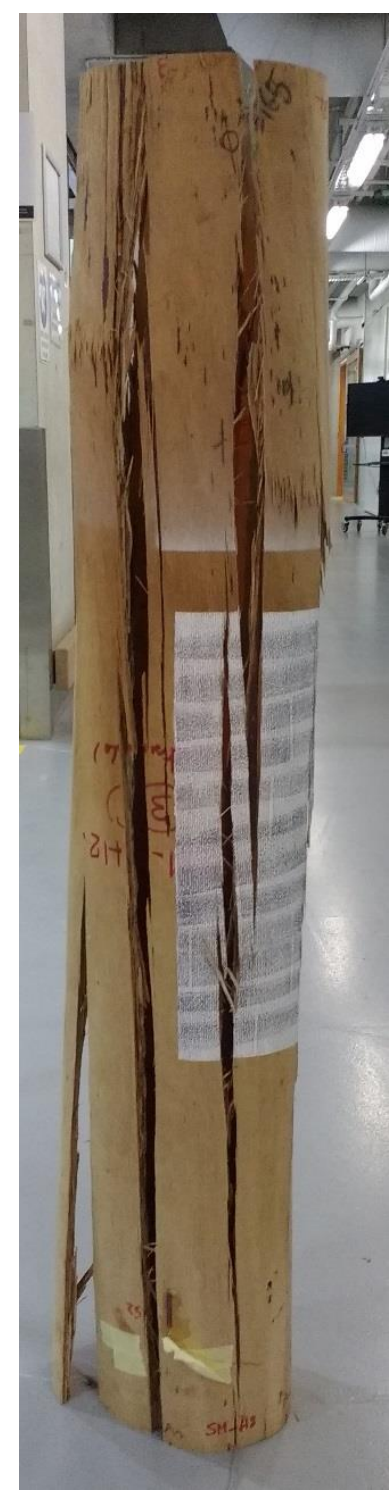

(b)

$620 \quad$ Figure 13: Compression tests failure modes, (a) local buckling of the wall for the compact sections 621 (shown for $C_{-} G 1$ ) and (b) sudden failure with the sections bursting into strips for the slender sec622 tions with no cross-banded veneers (shown for $S \_G 2$ ) 
4 x N12 bars

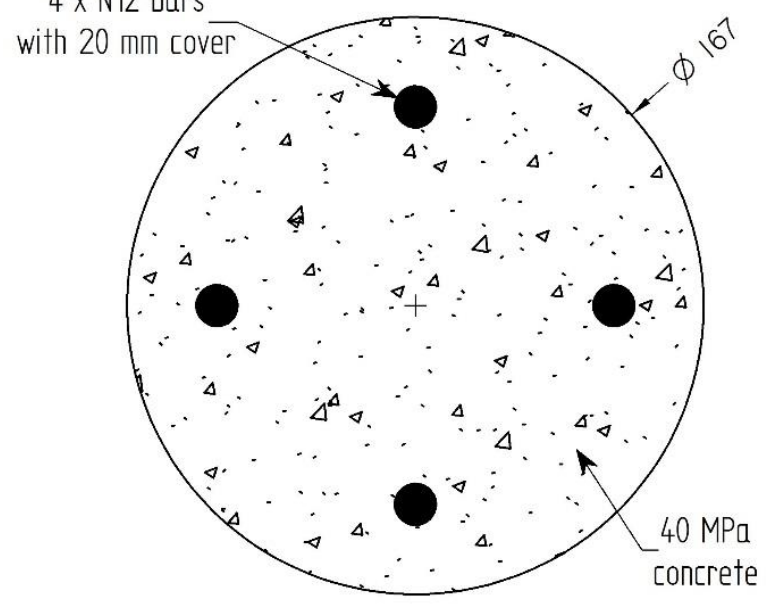

Figure 14: Concrete section used for comparison purposes 
Table 1: Average compressive and tensile strengths of the material (numbers in brackets indicate the number of tests on which the average and Coefficient of Variation $(\mathrm{CoV})$ are calculated)

\begin{tabular}{|c|c|c|c|c|c|c|c|c|}
\hline \multirow[b]{2}{*}{ Set } & \multicolumn{4}{|c|}{ Half cross-section $1^{(1)}$} & \multicolumn{4}{|c|}{ Half cross-section $2^{(1)}$} \\
\hline & $\begin{array}{l}\sigma_{\text {comp }} \\
(\mathrm{MPa})\end{array}$ & $\begin{array}{l}\mathrm{CoV} \\
(\%)\end{array}$ & $\begin{array}{c}\sigma_{\text {tens }} \\
(\mathrm{MPa})\end{array}$ & $\begin{array}{l}\mathrm{CoV} \\
(\%)\end{array}$ & $\begin{array}{c}\sigma_{\text {comp }} \\
(\mathrm{MPa})\end{array}$ & $\begin{array}{l}\mathrm{CoV} \\
(\%)\end{array}$ & $\begin{array}{c}\sigma_{\text {tens }} \\
(\mathrm{MPa})\end{array}$ & $\begin{array}{l}\mathrm{CoV} \\
(\%)\end{array}$ \\
\hline S_G1 & $61.2(3)$ & 4.2 & $109.5(5)$ & 21.4 & $58.6(3)$ & $<0.1$ & $96.7(3)$ & 7.3 \\
\hline S_G2 & $65.5(3)$ & 5.3 & $101.0(4)$ & 31.1 & $69.2(3)$ & 3.5 & $119.1(5)$ & 11.4 \\
\hline S_G3 & $72.7(3)$ & 3.2 & $114.0(5)$ & 31.9 & $77.9(3)$ & 3.4 & $--^{(2)}$ & $--^{(2)}$ \\
\hline S_G2_Cross ${ }^{(3)}$ & $54.0(3)$ & 0.5 & $94.4(5)$ & 5.3 & $59.9(2)$ & 12.3 & $88.9(5)$ & 15.7 \\
\hline C_G1 & $67.0(2)$ & 1.9 & $99.3(5)$ & 6.9 & $64.4(4)$ & 3.4 & $96.3(5)$ & 7.7 \\
\hline C_G2 & $67.8(2)$ & 7.2 & $117.2(5)$ & 8.7 & $66.7(4)$ & 1.6 & $134.0(5)$ & 11.8 \\
\hline C_G3 & $77.9(2)$ & 3.6 & $133.0(5)$ & 8.8 & $71.3(3)$ & 2.4 & $135.8(5)$ & 11.5 \\
\hline
\end{tabular}

631

632

633

634

635

636

637

638

639

640

(1): Half cross-section \#1 in tension and half cross-section \#2 in compression during the bending and shear tests

(2): Samples lost by the external company which $\mathrm{CNC}$ cut the samples

(3): Strengths calculated using the gross measured cross-sectional area which includes cross-banded veneers

Table 2: Average measured moisture content (MC) for material testing and full cross-sections (numbers in brackets indicate the number of samples on which the average and Coefficient of Variation $(\mathrm{CoV})$ are calculated)

\begin{tabular}{c|c|cc}
\hline Sample type & Test type & MC (\%) & CoV (\%) \\
\hline Material testing & Compression & $13.7(10)$ & 3.4 \\
& Tension & $11.3(14)$ & 5.7 \\
Full cross-sections & Bending & $13.7(4)$ & 4.2 \\
& Shear & $12.2(4)$ & 1.9 \\
\hline
\end{tabular}

Table 3: Bending tests results

\begin{tabular}{c|ccc|c}
\hline Set & $\begin{array}{c}\text { Capacity } \\
M_{b} \\
(\mathrm{kN} . \mathrm{m})\end{array}$ & $\begin{array}{c}\text { Strength } f_{b} \\
(\mathrm{MPa})\end{array}$ & $\begin{array}{c}\mathrm{MOE} E_{s} \\
(\mathrm{MPa})\end{array}$ & Failure mode \\
\hline S_G1 & 20.1 & 96.9 & 20154 & Compression (buckling) failure \\
S_G2 & 21.0 & 96.3 & 23252 & Tension failure \\
S_G3 & 24.6 & 116.7 & 27883 & $\begin{array}{c}\text { Compression (buckling) failure } \\
\text { S_G2_Cross }\end{array}$ \\
C_G1 & 19.3 & 88.5 & 14947 & Failure in joint between 1/2 cross-sections \\
C_G2 & 38.7 & 116.1 & 18590 & Tension failure \\
C_G3 & 39.1 & 119.0 & 21666 & Failure at support with steel clamps \\
\hline
\end{tabular}


Table 4: Shear tests results

\begin{tabular}{c|cc}
\hline Set & Capacity $V_{s}(\mathrm{kN})$ & Strength $f_{s}(\mathrm{MPa})$ \\
\hline S_G1 & 30.5 & 10.3 \\
S_G2 & 29.5 & 9.5 \\
S_G3 & 30.9 & 9.9 \\
S_G2_Cross ${ }^{(1)}$ & 32.0 & 10.4 \\
C_G1 & 53.9 & 9.5 \\
C_G2 & 60.8 & 10.7 \\
C_G3 & 58.5 & 10.6 \\
\hline
\end{tabular}

(1): Strength $f_{s}$ calculated using the gross measured cross-section which includes cross-banded veneers

Table 5: Compression tests results

\begin{tabular}{c|ccc|cc}
\hline Set & $\begin{array}{c}\text { Capacity } \\
R_{c}(\mathrm{kN})\end{array}$ & $\begin{array}{c}\text { Strength } f_{c} \\
(\mathrm{MPa})\end{array}$ & $\begin{array}{c}\text { MOE } E_{s} \\
(\mathrm{MPa})\end{array}$ & $\begin{array}{c}\text { Section strength } f_{c} / \\
\text { material strength } \sigma_{c o m p}\end{array}$ & $\begin{array}{c}E_{s} \text { (bending) / } \\
E_{s} \text { (compression) }\end{array}$ \\
\hline S_G1 & 438.2 & 68.6 & 18824 & 1.15 & 1.07 \\
S_G2 & 451.4 & 70.0 & 20592 & 1.04 & 1.13 \\
S_G3 & 488.0 & 80.3 & 24709 & 1.07 & 1.13 \\
S_G2_Cross & & 0.91 \\
C_G1 & 372.3 & 58.4 & 16343 & 1.02 & 1.04 \\
C_G2 & 784.0 & 72.0 & 17852 & 1.10 & 1.04 \\
C_G3 & 897.8 & 80.4 & 20849 & 1.20 & 0.95 \\
\hline
\end{tabular}

Table 6: Structural efficiency of circular timber, steel and reinforced concrete sections

\begin{tabular}{c|ccc|cc|ccc}
\hline \multirow{2}{*}{ Section } & \multicolumn{3}{|c|}{ Bending } & \multicolumn{3}{c|}{ Shear } & \multicolumn{3}{c}{ Compression } \\
& $\begin{array}{c}M_{b} \\
(\mathrm{kN} . \mathrm{m})\end{array}$ & $\begin{array}{c}M_{b} / \text { linear } \\
\text { weight }\end{array}$ & $\begin{array}{c}\text { Stiffness } \\
(\mathrm{kN} . \mathrm{m} / \mathrm{kg})\end{array}$ & $\begin{array}{c}V_{s} \\
\left(\mathrm{kNN} . \mathrm{m}^{2}\right)\end{array}$ & $\begin{array}{c}V_{s} / \text { linear } \\
\text { weight } \\
(\mathrm{kN} / \mathrm{kg})\end{array}$ & $\begin{array}{c}R_{c} \\
(\mathrm{kN})\end{array}$ & $\begin{array}{c}R_{c} / \text { linear } \\
\text { weight } \\
(\mathrm{kN} / \mathrm{kg})\end{array}$ & $\begin{array}{c}\text { Stiff- } \\
\text { ness } E A \\
(\mathrm{kN})\end{array}$ \\
\hline Timber (C_G2) & 39.1 & 4.4 & $6.15 \times 10^{2}$ & 60.8 & 6.8 & 897.8 & 100.0 & $2.37 \times 10^{5}$ \\
Steel $(168 \times 4.8)$ & 44.8 & 2.3 & $1.65 \times 10^{3}$ & 311.2 & 16.1 & 864.5 & 44.6 & $4.94 \times 10^{5}$ \\
Concrete & 11.9 & 0.2 & $1.22 \times 10^{3}$ & 92.0 & 1.8 & 946.4 & 18.0 & $7.18 \times 10^{5}$ \\
\hline
\end{tabular}

